\title{
標準，非標準特異䎼動システムにおける $\boldsymbol{H}_{\infty}$ 制御問題のための 再帰的アルゴリズム†
}

\author{
向 谷 博 明*・水上 孝 一**・徐驊** \\ The Recursive Algorithm of $H_{\infty}$ Control Problems for Standard and Nonstandard \\ Singularly Perturbed Systems
}

Hiroaki Mukaidani*, Koichi Mizukami**, and Hua Xu**

\begin{abstract}
Making use of the recursive technique, we consider the $H_{\infty}$ control problem for singularly perturbed systems which include the nonstandard case. We construct the controller that guarantees a disturbance attenuation level $\gamma$ which is larger than the maximum of the optimal disturbance attenuation levels for the slow and fast subsystems. In order to obtain the controller, we must solve the full-order Riccati equations. Using the recursive technique, we show that the solution of the full-order Riccati equation converges to a positive semidefinite stabilizing solution with the rate of convergence of $O\left(\varepsilon^{k}\right)$. In addition, the controller achieves the peformance level $\gamma+O\left(\varepsilon^{k+1}\right)$. To show the effectiveness of the proposed algorithm, numerical examples are included.
\end{abstract}

Key Words : $H_{\infty}$ control problems, recursive technique, nonstandard singularly perturbed systems

\section{1.はじめに}

近年, $A_{22}^{-1}$ が存在する標準特異摂動システムにおける $H_{\infty}$ 制御問題に関して,さまざまな研究が行われている1) 4). Z. $\operatorname{Pan}^{1), 2)}$ らは, 微分ゲーム理論に基づき, 特異摂動法を利用し て制御器を構築している.しかし,この設計法によれば, $A_{22}^{-1}$ の存在が必要である.さらに, composite 制御器の場合, 設計 仕様 $\gamma$ に対して $O(\varepsilon)$ 程度の精度しか保証されない.一方, E. Fridman $^{3)}$ によって, high-order である正確な制御器をえる ためのアルゴリズムの研究報告がある.この設計法によれば， $A_{22}^{-1}$ が存在する仮定は必要でないが, 補助的な状態変数を導 入しなければならないため, システムの高次元化，ならびに， 制御器の設計に外部展開(outer expantion)を利用している ため, 微分係数の計算が増加するなどの傾向がある.

著者らは文献 13)，14）において, 非標準特異摂動システム における最適レギュレータ問題や LQG 問題の制御器の設計 に欠かせない摂動項 $(\varepsilon)$ を含むりカッチ方程式を解くための 再帰的アルゴリズムを提案した。しかし, 再帰的アルゴリズ

$†$ 第 5 回計測自動制御学会中国支部学術講演会で発表 $(1996 \cdot 11)$

* 広島市立大学情報科学部 広島市安佐南区大塚東 3-4-1

** 広島大学総合科学部 東広島市鏡山 1-7-1

* Faculty of Information Sciences, Hiroshima City University, Asaminami-ku, Hiroshima

** Faculty of Integrated Arts and Sciences, Hiroshima University, Higashi-Hiroshima

(Received November 1, 1996)

(Revised December 1, 1997)
ム 7),9)を利用した $H_{\infty}$ 制御に関する数值解法は研究されてい ない.この理由は, 制御器を構築するためのリカッチ方程式 がゲーム型のリカッチ方程式 $\left(P_{\varepsilon}\right.$ の 2 次項の係数行列が, 正 定とは限らない)であり, 従来の仮定である可制御性や可観測 性の条件のもとでは, 再帰的アルゴリズムを利用して得られ た解が準正定かつ安定化解である保証がないためである.

本論文では， $A_{22}^{-1}$ の存在を仮定しない非標準特異提動シス テムにおける $H_{\infty}$ 制御問題に対して, 文献 13), 14)の再帰的 アルゴリズムの手法を拡張した制御器の構築を提案する. 本 論文では, 特異摂動法を用いずに, 直接 full-order system に おけるリカッチ方程式の解を $k$ 回の繰り返し計算によって, $O\left(\varepsilon^{k}\right)$ の高精度で解くことを示す.このとき, 構築された制御 器は, 直接 full-オーダのリカッチ方程式を解いて構築した制 御器と比較して, $O\left(\varepsilon^{k}\right)$ の高精度であるので, 特異摂動法によ る近似解を利用した制御器に比べて, より最適である。つま り, 再帰的アルゴリズムによってえられた制御器は, 設計仕 様の $\gamma$ に対して $\gamma+O\left(\varepsilon^{k+1}\right)$ を保証する. 以上から, 本論文で は, E. Fridman ${ }^{3)}$ が提案している外部展開を利用した highorder な制御器の設計方法と異なり, 再帰的アルゴリズムを 利用して高精度の制御器を設計しているところに大きな特徵 がある。

本論文では, 以下の記号を用いる. $\|X\|_{s}$ は, 実行列 $X \in$ $\mathbf{R}^{k_{1} \times k_{1}}$ の最大特異值 $\|X\|_{s} \equiv\left[\lambda_{\max }\left(X^{T} X\right)\right]^{1 / 2},\|G(s)\|_{\infty}$ は, 伝達 関数 行列 $G(s) \in \mathbf{R}^{k_{2} \times k_{2}}$ の $H_{\infty}$ ノルム $\|G(s)\|_{\infty} \equiv$ $\sup _{s}\left[\lambda_{\max }\left(G^{*}(s) G(s)\right)\right]^{1 / 2}(s=j \omega, \omega \in \mathbf{R}),\|h(t)\|_{2}$ は，時間関 数べクトル $h(t) \in \mathbf{R}^{k_{3}}$ の $L_{2}[0, \infty]$ ノルム $\|h(t)\|_{2} \equiv$ 
$\left[\int_{0}^{\infty} h^{T}(t) h(t) d t\right]^{1 / 2}(t \in \mathbf{R}),|x|_{E}$ は, 実べクトル $x \in \mathbf{R}^{k_{4}}$ のユー クッリドノルム $|x|_{E} \equiv\left[x^{T} x\right]^{1 / 2}$ をれぞれあらわす。

\section{2. 問題設定}

\section{1 特異摂動システム}

システムに摂動項を含む状態空間において，以下のような 線形時不変特異摂動システムを考光る ${ }^{3)}$.

$$
\dot{x}_{1}=A_{11} x_{1}+A_{12} x_{2}+B_{11} w+B_{21} u, \quad x_{1}(0)=0
$$

$\varepsilon \dot{x}_{2}=A_{21} x_{1}+A_{22} x_{2}+B_{12} w+B_{22} u, \quad x_{2}(0)=0$

このシステムに対する 2 次評価関数は (2)である.

$$
J=\int_{0}^{\infty} z^{T}(t) z(t) d t
$$

ただし，

$$
z=C x+D u
$$

である.ジステム $(1 \mathrm{~b})$ 中の $\varepsilon$ は摂動項に相当する十分小さな 正のパラメータ, $x(t)=\left[\begin{array}{ll}x_{1}^{T}(t) & x_{2}^{T}(t)\end{array}\right]^{T}$ は $x_{i}(t) \in \mathbf{R}^{n_{i}}(i=1$, 2)である状態べクトル, $u(t) \in \mathbf{R}^{m}$ は制御入力, $w(t) \in \mathbf{R}^{r}$ は 外乱, $z(t) \in \mathbf{R}^{l}$ は制御量である。また，各係数行列は適当な 次元をもつと仮定する。ここで, システム $(1 \mathrm{a}) \sim(1 \mathrm{~b})$ におい て， $A_{22}$ が特異である,つまり, $A_{22}^{-1}$ が存在しないシステムを 一般に非標準特異摂動システムと呼ぶ。

続いて，以下の行列を定義する.

$$
\begin{aligned}
Q & =C^{T} C=\left[\begin{array}{ll}
Q_{11} & Q_{12} \\
Q_{12}^{T} & Q_{22}
\end{array}\right] \\
& =\left[\begin{array}{ll}
C_{1}^{T} C_{1} & C_{1}^{T} C_{2} \\
C_{2}^{T} C_{1} & C_{2}^{T} C_{2}
\end{array}\right] \geq 0 \\
S_{2 j}^{\gamma} & =B_{2 i} B_{2 j}^{T}-\gamma^{-2} B_{1 i} B_{1 j}^{T}, \quad i=1,2, \quad j=1,2 \\
B_{1 \varepsilon} & =\left[\begin{array}{cc}
B_{11} \\
\varepsilon^{-1} B_{12}
\end{array}\right], \quad B_{2 \varepsilon}=\left[\begin{array}{c}
B_{21} \\
\varepsilon^{-1} B_{22}
\end{array}\right] \\
A_{\varepsilon} & =\left[\begin{array}{cc}
A_{11} & A_{12} \\
\varepsilon^{-1} A_{21} & \varepsilon^{-1} A_{22}
\end{array}\right] \\
S_{\varepsilon}^{\gamma} & =\left[\begin{array}{cc}
S_{11}^{\gamma} & \varepsilon^{-1} S_{12}^{\gamma} \\
\varepsilon^{-1} S_{12}^{T \gamma} & \varepsilon^{-2} S_{22}^{\gamma}
\end{array}\right]
\end{aligned}
$$

また，以下の仮定を導入する1),

[仮定 1] 行列対 $\left(A_{\varepsilon}, B_{1 \varepsilon}\right),\left(A_{\varepsilon}, B_{2 \varepsilon}\right)$ はともに可安定であ $\eta$, また同時に行列対 $\left(A_{\varepsilon}, C\right)$ は可検出である摂動項 $\varepsilon \in(0$, $\left.\varepsilon_{0}\right], \varepsilon_{0}>0$ が存在する.

以上の[仮定 1]のもと， $H_{\infty}$ 制御問題とは,

（条件 1） 状態フィードバック $u=K x$ によって,閉ループシ ステム (1 a)〜 (1 b) を内部安定にする.

(条件 2) システム $(1 \mathrm{a}) \sim(1 \mathrm{~b})$ における外乱 $w$ から制御量 $z$ にいたる伝達関数 $G_{\varepsilon}$ の $H_{\infty}$ ノルム $\left\|G_{\varepsilon}\right\|_{\infty}$ をある与えられ た設計仕様 $\gamma$ 以下，すなわち $\left\|G_{\varepsilon}\right\|_{\infty}<\gamma$ にする。ただし，

$$
G_{\varepsilon}=(C+D K) \cdot\left(s I-A_{\varepsilon}-B_{2 \varepsilon} K\right)^{-1} B_{1 \varepsilon}
$$

ここで, 制御器の存在性に関係する前提条件として, 以下の 仮定を設定する。

[仮定 2] $C^{T} D=0$ (直交条件), $D^{T} D=I$ (正規化条件)

以上の $H_{\infty}$ 制御問題に対して,システム $(1 \mathrm{a}) \sim(1 \mathrm{~b})$ 及び評 価関数 $(2)$ に対する $H_{\infty}$ 制御器は以下の $(4) \sim(5)$ によって
与えられる(1),5),6),8).

リカッチ方程式 ( 4 )

$$
P_{\varepsilon} A_{\varepsilon}+A_{\varepsilon}^{T} P_{\varepsilon}-P_{\varepsilon} S_{\varepsilon}^{\gamma} P_{\varepsilon}+Q=0
$$

が準正定である安定化解，すなわち， $P_{\varepsilon} \geq 0$ かつ，行列 $A_{\varepsilon}$ $-S_{\varepsilon}^{\gamma} P_{\varepsilon}$ が安定であるような解をもつとき, 制御器の制御入力

$$
u(t)=-B_{2 \varepsilon}^{T} P_{\varepsilon} x(t)=K x(t)
$$

は, $\left\|G_{\varepsilon}\right\|_{\infty}<\gamma$ を満足する。ただし，

$$
P_{\varepsilon}=\left[\begin{array}{ll}
P_{11}(\varepsilon) & \varepsilon P_{21}^{T}(\varepsilon) \\
\varepsilon P_{21}(\varepsilon) & \varepsilon P_{22}(\varepsilon)
\end{array}\right]
$$

である。

\subsection{0 -オーダ方程式の導出}

まず，full-オーダリカッチ方程式 ( 4 )を一般化リカッチ方 程式に変換する補題をあげる13),14)。

[補題 1] full-オーダリカッチ方程式 (4)は，以下の一般化 リカッチ方程式 $(7 \mathrm{a}) \sim(7 \mathrm{~b})$ を解くことに等価である.

$$
\begin{aligned}
& P^{T} A+A^{T} P-P^{T} S^{\gamma} P+Q=0 \\
& P_{\varepsilon}=\bar{D}^{T} P=P^{T} \bar{D}
\end{aligned}
$$

このとき, $(5)$ で与えられる制御入力 $u(t)$ は以下によって 変形できる.

$$
u(t)=-B_{2}^{T} P x(t)=K x(t)
$$

ただし

$$
\begin{aligned}
& \bar{D}=\left[\begin{array}{ll}
I & 0 \\
0 & \varepsilon I
\end{array}\right], \quad P=\left[\begin{array}{ll}
P_{11} & \varepsilon P_{21}^{T} \\
P_{21} & P_{22}
\end{array}\right] \\
& A=\left[\begin{array}{ll}
A_{11} & A_{12} \\
A_{21} & A_{22}
\end{array}\right], \quad S^{\gamma}=\left[\begin{array}{ll}
S_{11}^{\gamma} & S_{12}^{\gamma} \\
S_{12}^{\gamma T} & S_{22}^{\gamma}
\end{array}\right] \\
& B_{2}=\left[\begin{array}{l}
B_{21} \\
B_{22}
\end{array}\right]
\end{aligned}
$$

次に，一般化リカッチ方程式 $(7 \mathrm{a}) \sim(7 \mathrm{~b})$ における再帰的 アルゴリズムを導出する。方程式 $(7 \mathrm{a})$ ～(7 b ) を各ブロック ごとに計算する。

$$
\begin{aligned}
& A_{11}^{T} P_{11}+P_{11}^{T} A_{11}+A_{21}^{T} P_{21}+P_{21}^{T} A_{21} \\
& \quad-P_{11}^{T} S_{11}^{\gamma} P_{11}-P_{21}^{T} S_{22}^{\gamma} P_{21} \\
& \quad-P_{11}^{T} S_{12}^{\gamma} P_{21}-P_{21}^{T} S_{12}^{\gamma} P_{11}+Q_{11}=0 \\
& \varepsilon P_{21} A_{11}+P_{22}^{T} A_{21}+A_{12}^{T} P_{11}+A_{22}^{T} P_{21} \\
& \quad-\varepsilon P_{21} S_{11}^{\gamma} P_{11}-\varepsilon P_{21} S_{12}^{\gamma} P_{21} \\
& \quad-P_{22}^{T} S_{12}^{T} P_{11}-P_{22}^{T} S_{22}^{\gamma} P_{21}+Q_{12}^{T}=0 \\
& A_{22}^{T} P_{22}+P_{22}^{T} A_{22}+\varepsilon A_{12}^{T} P_{21}^{T}+\varepsilon P_{21} A_{12} \\
& \quad-P_{22}^{T} S_{22}^{\gamma} P_{22}-\varepsilon P_{22}^{T} S_{12}^{\gamma T} P_{21}^{T} \\
& \quad-\varepsilon P_{21} S_{12}^{\gamma} P_{22}-\varepsilon^{2} P_{21} S_{11}^{\gamma} P_{21}^{T}+Q_{22}=0
\end{aligned}
$$

続いて, リカッチ方程式 $(9 \mathrm{a}) \sim(9 \mathrm{c})$ において $\varepsilon=0$ とすれ ば，方程式 (10 a ) (10 c) を得る.ここで, 0 -オーダ方程式の 解を $\bar{P}_{11}, \bar{P}_{21}, \bar{P}_{22}$ とおく。

$$
\begin{gathered}
A_{11}^{T} \bar{P}_{11}+\bar{P}_{11}^{T} A_{11}+A_{21}^{T} \bar{P}_{21}+\bar{P}_{21}^{T} A_{21} \\
\quad-\bar{P}_{11}^{T} S_{11}^{\gamma} \bar{P}_{11}-\bar{P}_{21}^{T} S_{22}^{\gamma} \bar{P}_{21} \\
-\bar{P}_{11}^{T} S_{12}^{\gamma} \bar{P}_{21}-\bar{P}_{21}^{T} S_{12}^{\gamma T} \bar{P}_{11}+Q_{11}=0 \\
\bar{P}_{22}^{T} A_{21}+A_{12}^{T} \bar{P}_{11}+A_{22}^{T} \bar{P}_{21}-\bar{P}_{22}^{T} S_{12}^{\gamma} \bar{P}_{11} \\
\quad-\bar{P}_{22}^{T} S_{22}^{\gamma} \bar{P}_{21}+Q_{12}^{T}=0 \\
A_{22}^{T} \bar{P}_{22}+\bar{P}_{22}^{T} A_{22}-\bar{P}_{22}^{T} S_{22}^{\gamma} \bar{P}_{22}+Q_{22}=0 \\
\text { ここで, 以下の仮定を導入する } \\
\end{gathered}
$$


[仮定 3] 行列対 $\left(A_{22}, B_{22}\right)$ は可安定であり, かつ行列対 $\left(A_{22}, C_{2}\right)$ は可観測である.

また, リカッチ方程式 $(10 \mathrm{c})$ において $\gamma_{f}$ を以下のように定 める3),12).

$\gamma_{f}=\inf \{\gamma>0 \mid$ リカッチ方程式 (10 c) が正定である安定化解 $\bar{P}_{22}$ をつつ. $\}$

このとき, $\gamma>\gamma_{f}$ をみたすすべての $\gamma$ に対して, 方程式(10 c) は正定対称かつ安定化解をもつので行列 $A_{22}-S_{22}^{\gamma} \bar{P}_{22}$ は非 特異である.したがって, $\left(A_{22}-S_{22}^{\gamma} \bar{P}_{22}\right)^{-1}$ は存在する. 以上 から 0-オーダ方程式(11 a ) (11c)がえられる.

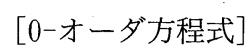

$$
\begin{aligned}
& \bar{P}_{11}^{T} A_{0}^{\gamma}+A_{0}^{\gamma T} \bar{P}_{11}-\bar{P}_{11}^{T} S_{0}^{\gamma} \bar{P}_{11}+Q_{0}^{\gamma}=0 \\
& \bar{P}_{21}=-N_{2}^{T}+N_{1}^{T} \bar{P}_{11} \\
& A_{22}^{T} \bar{P}_{22}+\bar{P}_{22}^{T} A_{22}-\bar{P}_{22}^{T} S_{22}^{\gamma} \bar{P}_{22}+Q_{22}=0
\end{aligned}
$$
ただし

$$
\begin{aligned}
& A_{0}^{\gamma}=A_{11}+N_{1} A_{21}+S_{12}^{\gamma} N_{2}^{T}+N_{1} S_{22}^{\gamma} N_{2}^{T} \\
& S_{0}^{\gamma}=S_{11}^{\gamma}+N_{1} S_{12}^{\gamma T}+S_{12}^{\gamma} N_{1}^{T}+N_{1} S_{22}^{\gamma} N_{1}^{T} \\
& Q_{0}^{\gamma}=Q_{11}-N_{2} A_{21}-A_{21}^{T} N_{2}^{T}-N_{2} S_{22}^{\gamma} N_{2}^{T} \\
& N_{2}^{T}=\bar{A}_{22}^{-T} \bar{Q}_{12}^{T}, \quad N_{1}^{T}=-\bar{A}_{22}^{-T} \bar{A}_{12}^{T} \\
& \bar{A}_{12}=A_{12}-S_{12}^{\gamma} \bar{P}_{22}, \quad \bar{A}_{22}=A_{22}-S_{22}^{\gamma} \bar{P}_{22} \\
& \bar{Q}_{12}=Q_{12}+A_{21}^{T} \bar{P}_{22} .
\end{aligned}
$$

（注意 1） 行列 $A_{0}^{\gamma}, S_{0}^{\gamma}, Q_{0}^{\gamma}$ を記述する公式の中には，リカッ 于方程式 (11 c) の解 $\bar{P}_{22}$ が含まれているが,

$$
\begin{array}{ll}
T_{1}=\left[\begin{array}{cc}
A_{11} & -S_{11}^{\gamma} \\
-Q_{11} & -A_{11}^{T}
\end{array}\right], & T_{2}=\left[\begin{array}{cc}
A_{12} & -S_{12}^{\gamma} \\
-Q_{12} & -A_{21}^{T}
\end{array}\right] \\
T_{3}=\left[\begin{array}{cc}
A_{21} & -S_{12}^{\gamma} \\
-Q_{12}^{T} & -A_{12}^{T}
\end{array}\right], & T_{4}=\left[\begin{array}{cc}
A_{22} & -S_{22}^{\gamma} \\
-Q_{22} & -A_{22}^{T}
\end{array}\right]
\end{array}
$$

に対し，

$$
T_{0}=T_{1}-T_{2} T_{4}^{-1} T_{3}=\left[\begin{array}{cc}
A_{0}^{\gamma} & -S_{0}^{\gamma} \\
-Q_{0}^{\gamma} & -A_{0}^{\gamma T}
\end{array}\right]
$$

が成立するので実際には, 行列 $A_{0}^{\gamma}, S_{0}^{\gamma}, Q_{0}^{\gamma}$ はリカッチ方程式 (11 c)の解 $\bar{P}_{22}$ に依存しない13),14).

リカッチ方程式(11 a)が正定である安定化解をもつため に, 以下の仮定を導入する ${ }^{12)}$.

[仮定 4] $Q_{i j}=C_{i}^{T} C_{j}(i, j=1,2)$ とする.このとき，

$$
\begin{aligned}
& \operatorname{rank}\left[\begin{array}{ccc}
S I_{n_{1}}-A_{11} & -A_{12} & B_{21} \\
-A_{21} & -A_{22} & B_{22}
\end{array}\right]=n_{1}+n_{2} \\
& \operatorname{rank}\left[\begin{array}{ccc}
S I_{n_{1}}-A_{11}^{T} & -A_{21}^{T} & C_{1}^{T} \\
-A_{12}^{T} & -A_{22}^{T} & C_{2}^{T}
\end{array}\right]=n_{1}+n_{2}
\end{aligned}
$$

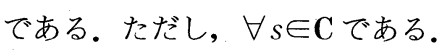

（注意 2）［仮定 4]が成立することは, $\gamma>\gamma_{f}$ を満たすすべて の $\gamma$ に対して, 行列対 $\left(A_{0}^{\gamma}, \hat{B}_{0}^{\gamma}\right)$ は可安定であり, かつ行列対 $\left(A_{0}^{\gamma}, C_{0}^{\gamma}\right)$ は可観測であることと等価である ${ }^{12)}$. ただし,

$$
\begin{aligned}
& Q_{0}^{\gamma}=C_{0}^{\gamma T} C_{0}^{\gamma}, \quad C_{0}^{\gamma}=C_{1}+C_{2} M_{1}^{T} \\
& M_{1}=-\tilde{A}_{21} \tilde{A}_{22}^{-1} \\
& \tilde{A}_{21}=A_{21}^{T}+Q_{12} \bar{P}_{22}^{-1} \\
& \tilde{A}_{22}=A_{22}^{T}+Q_{22} \bar{P}_{22}^{-1} \\
& S_{0}^{\gamma}=\hat{B}_{0}^{\gamma} \widehat{B}_{0}^{\gamma T}-\gamma^{-2} \bar{B}_{0}^{\gamma} \bar{B}_{0}^{\gamma T} \\
& \tilde{B}_{0}^{\gamma}=B_{21}+N_{1} B_{22}=B_{21}-\bar{A}_{12} \bar{A}_{22}^{-1} B_{22}
\end{aligned}
$$

$\bar{B}_{0}^{\gamma}=B_{11}+N_{1} B_{12}=B_{11}-\bar{A}_{12} \bar{A}_{22}^{-1} B_{12}$

である。

次に, リカッチ方程式(11 a)において $\gamma_{s}$ を以下のように定 める12).

$\gamma_{s}=\inf \{\dot{\gamma}>0 \mid$ リカッチ方程式(11 a)が正定である安定化解 $\bar{P}_{11}$ をつ. $\}$

以上から,リカッチ方程式(11 a)，(11c) は $\gamma>\bar{\gamma}$ を満たす すべての $\gamma$ に対して, 正定対称である安定化解をもつ. ただ し, $\bar{\gamma}=\max \left\{\gamma_{s}, \gamma_{f}\right\}$ とする.

\section{3 再帰的アルゴリズムの導出}

再帰的アルゴリズムを導出するために，偏差を定義する.

$$
\begin{aligned}
& P_{11}=\bar{P}_{11}+\varepsilon E_{11}, \quad P_{21}=\bar{P}_{21}+\varepsilon E_{21} \\
& P_{22}=\bar{P}_{22}+\varepsilon E_{22}
\end{aligned}
$$

以上を方程式 (9a)〜 (9c) に代入する. 0-オーダ方程式 (10 a) 〜 $(10 \mathrm{c})$ を用いて, 偏差 $E$ についての方程式 $(16 \mathrm{a}) \sim(16 \mathrm{c})$ が得られる。

$$
\begin{aligned}
E_{11}^{T} \bar{A}_{0}+\bar{A}_{0}^{T} E_{11}= & -V^{T} H_{1}^{T}-H_{1} V \\
& +V^{T} H_{3} V+\varepsilon H_{2} \\
E_{11}^{T} \bar{A}_{12}+E_{21}^{T} \bar{A}_{22} & +\bar{A}_{21}^{T} E_{22}=H_{1} \\
E_{22}^{T} \bar{A}_{22}+\bar{A}_{22}^{T} E_{22}= & H_{3}
\end{aligned}
$$
ただし

$$
\begin{aligned}
H_{1}= & -A_{11}^{T} P_{21}^{T}+P_{11}^{T} S_{11}^{\gamma} P_{21}^{T}+P_{21}^{T} S_{12}^{\gamma T} P_{21}^{T} \\
& +\varepsilon\left(E_{11}^{T} S_{12}^{\gamma} E_{22}+E_{21}^{T} S_{22}^{\gamma} E_{22}\right) \\
H_{2}= & E_{11}^{T} S_{11}^{\gamma} E_{11}+E_{21}^{T} S_{22}^{\gamma} E_{21} \\
& +E_{11}^{T} S_{12}^{\gamma} E_{21}+E_{21}^{T} S_{12}^{\gamma T} E_{11} \\
H_{3}= & -A_{12}^{T} P_{21}^{T}-P_{21} A_{12}+\varepsilon P_{21} S_{11}^{\gamma} P_{21}^{T} \\
& +\varepsilon E_{22}^{T} S_{22}^{\gamma} E_{22}+P_{21} S_{12}^{\gamma} P_{22}+P_{22}^{T} S_{12}^{\gamma T} P_{21}^{T} \\
\bar{A}_{11}= & A_{11}-S_{11}^{\gamma} \bar{P}_{11}-S_{12}^{\gamma} \bar{P}_{21}, \quad \overline{A_{0}}=\overline{A_{11}}-\bar{A}_{12} \bar{A}_{22}^{-1} \bar{A}_{21} \\
\bar{A}_{21}= & A_{21}-S_{12}^{\gamma T} \bar{P}_{11}-S_{22}^{\gamma} \bar{P}_{21}, \quad V=\bar{A}_{22}^{-1} \bar{A}_{21}
\end{aligned}
$$

したがって, 偏差 $E$ についての方程式 $(16 \mathrm{a}) \sim(16 \mathrm{c})$ を差分 化することによって, 偏差 $E$ についての再帰的アルゴリズム $(17 \mathrm{a}) \sim(17 \mathrm{c})$ が導出される.

$$
\begin{aligned}
& E_{11}^{(j+1) T} \overline{A_{0}}+\bar{A}_{0}^{T} E_{11}^{(j+1)} \\
& \quad=-V^{T} H_{1}^{(j) T}-H_{1}^{(j)} V+V^{T} H_{3}^{(j)} V+\varepsilon H_{2}^{(j)}
\end{aligned}
$$

$E_{11}^{(j+1) T} \bar{A}_{12}+E_{21}^{(j+1) T} \bar{A}_{22}+\bar{A}_{21}^{T} E_{22}^{(j+1)}=H_{1}^{(j)}$

$E_{22}^{(j+1) T} \bar{A}_{22}+\bar{A}_{22}^{T} E_{22}^{(j+1)}=H_{3}^{(j)}$ ただし

$$
\begin{aligned}
H_{1}^{(j)}= & -A_{11}^{T} P_{21}^{(j) T}+P_{11}^{(j) T} S_{11}^{\gamma} P_{21}^{(j) T} \\
& +P_{21}^{(j) T} S_{12}^{\gamma T} P_{21}^{(j) T} \\
& +\varepsilon\left(E_{11}^{(j) T} S_{12}^{\gamma} E_{22}^{(j)}+E_{21}^{(j) T} S_{22}^{\gamma} E_{22}^{(j)}\right) \\
H_{2}^{(j)}= & E_{11}^{(j) T} S_{11}^{\gamma} E_{11}^{(j)}+E_{21}^{(j) T} S_{22}^{\gamma} E_{21}^{(j)} \\
& +E_{11}^{(j) T} S_{12}^{\gamma} E_{21}^{(j)}+E_{21}^{(j) T} S_{12}^{\gamma T} E_{11}^{(j)} \\
H_{3}^{(j)}= & -A_{12}^{T} P_{21}^{(j) T}-P_{21}^{(j)} A_{12} \\
& +\varepsilon P_{21}^{(j)} S_{11}^{\gamma} P_{21}^{(j) T}+\varepsilon E_{22}^{(j) T} S_{22}^{\gamma} E_{22}^{(j)} \\
& +P_{21}^{(j)} S_{12}^{\gamma} P_{22}^{(j)}+P_{22}^{(j) T} S_{12}^{\gamma T} P_{21}^{(j) T} \\
P_{11}^{(j)}= & \bar{P}_{11}+\varepsilon E_{11}^{(j)}, \quad P_{21}^{(j)}=\bar{P}_{21}+\varepsilon E_{21}^{(j)} \\
P_{22}^{(j)}= & \bar{P}_{22}+\varepsilon E_{22}^{(j)}, \quad E_{11}^{(0)}=E_{21}^{(0)}=E_{22}^{(0)}=0
\end{aligned}
$$

ここで, ${ }^{(j)}$ は $j$ 番目の值, ${ }^{(j+1)}$ は $j+1$ 番目の值を意味する. したがって, $j$ 番目の值が求まれば, 逐次的に $j+1$ 番目の值 
が定まり，これを再帰的に求めればよい。

\section{3. 再帰的アルゴリズムの収束}

まず，定理をあげる。

《定理 $1 》 \varepsilon$ が十分小さいと仮定する.また, [仮定 1]～[仮 定 4]が成立するとする。このとき， $\gamma>\bar{\gamma}=\max \left\{\gamma_{s}, \gamma_{f}\right\}$ を満 足するある $\gamma$ に対して, アルゴリズム $(17 \mathrm{a}) \sim(17 \mathrm{c})$ は, 偏差 $E$ の正確な值に $O\left(\varepsilon^{k}\right)$ の高精度で収束する.すなわち,

$\left\|E-E^{(k)}\right\|_{s}=O\left(\varepsilon^{k}\right), \quad(k=1,2, \cdots)$

また，リカッチ方程式 ( 4 ) の準正定である安定化解 $P_{\varepsilon}$ は,

$$
P_{\varepsilon}=\left[\begin{array}{cc}
\bar{P}_{11}+\varepsilon E_{11} & \varepsilon\left(\bar{P}_{21}+\varepsilon E_{21}\right)^{T} \\
\varepsilon\left(\bar{P}_{21}+\varepsilon E_{21}\right) & \varepsilon\left(\bar{P}_{22}+\varepsilon E_{22}\right)
\end{array}\right]
$$

と表現できる。ただし

$$
E=\left[\begin{array}{ll}
E_{11} & E_{21} \\
E_{21}^{T} & E_{22}
\end{array}\right], \quad E^{(k)}=\left[\begin{array}{cc}
E_{11}^{(k)} & E_{21}^{(k)} \\
E_{21}^{(k) T} & E_{22}^{(k)}
\end{array}\right]
$$

（定理 1 の証明） まず，再帰的アルゴリズム（17 a ～（17 c) において, $\varepsilon=0$ の近傍における唯一解 $E$ の存在は陰関数定 理により証明できる ${ }^{9,13), 14)}$. 陰関数定理を用いるために, アル ゴリズム $(17 \mathrm{a}) \sim(17 \mathrm{c})$ に対するヤコビ行列を以下のように 計算する。

[ヤコビ行列]

$$
\left.J\right|_{\varepsilon=0}=\left[\begin{array}{ccc}
J_{11} & 0 & 0 \\
J_{21} & J_{22} & J_{23} \\
0 & 0 & J_{33}
\end{array}\right]
$$

ただし

$$
\begin{aligned}
J_{11}= & I \otimes \bar{A}_{0}+\bar{A}_{0}^{T} \otimes I \\
J_{22}= & I \otimes \bar{A}_{22} \\
J_{33}= & I \otimes \bar{A}_{22}+\bar{A}_{22}^{T} \otimes I \\
J_{k 1}= & \left.\frac{\partial L_{k}}{\partial E_{11}}\right|_{\varepsilon=0}, \quad J_{k 2}=\left.\frac{\partial L_{k}}{\partial E_{21}}\right|_{\varepsilon=0} \\
J_{k 3}= & \left.\frac{\partial L_{k}}{\partial E_{22}}\right|_{\varepsilon=0}, \quad(k=1,2,3) \\
L_{1}= & E_{11}^{T} \bar{A}_{0}+\bar{A}_{0}^{T} E_{11}+V^{T} H_{1}^{T}+H_{1} V \\
& -V^{T} H_{3} V-\varepsilon H_{2} \\
L_{2}= & E_{11}^{T} \bar{A}_{12}+E_{21}^{T} \bar{A}_{22}+\bar{A}_{21}^{T} E_{22}-H_{1} \\
L_{3}= & E_{22}^{T} \bar{A}_{22}+\bar{A}_{22}^{T} E_{22}-H_{3}
\end{aligned}
$$

冈はクロネッカ積である.ここで, $\bar{A}_{22}=A_{22}-S_{22}^{\gamma} \bar{P}_{22}$ はリカッ チ方程式 (11 c) が，安定化解をもつので安定である.同様に, $A_{0}^{\gamma}-S_{0}^{\gamma} \bar{P}_{11}$ は, リカッチ方程式(11 a) が, 安定化解をもつのて 安定である。したがって,

$$
A_{0}^{\gamma}-S_{0}^{\gamma} \bar{P}_{11}=\bar{A}_{11}-\overline{A_{12}} \bar{A}_{22}^{-1} \bar{A}_{21}=\overline{A_{0}}
$$

となるので, $\overline{A_{0}}$ は安定となる. 以上より, ヤコビ行列が非特 異であるから,陰関数定理を適用して再帰的アルゴリズム 17 a) 〜 $(17 \mathrm{c})$ に対する唯一解 $E$ の存在が証明される.

次に，再帰的アルゴリズム $(17 \mathrm{a}) \sim(17 \mathrm{c})$ の収束性につい て考える. 再帰的アルゴリズム $(17 \mathrm{a}) \sim(17 \mathrm{c})$ に対して $j=0$ と抢き，方程式 $(16 \mathrm{a}) \sim(16 \mathrm{c})$ との差をとる.

$$
\begin{aligned}
& \left(E_{11}-E_{11}^{(1)}\right) \overline{A_{0}}+\bar{A}_{0}^{T}\left(E_{11}-E_{11}^{(1)}\right) \\
& \quad=\varepsilon \mathcal{F}_{1}\left(E_{11}, E_{21}, \varepsilon\right)
\end{aligned}
$$

$$
\begin{aligned}
& \left(E_{21}-E_{21}^{(1)}\right)^{T} \bar{A}_{22}=\varepsilon \mathscr{F}_{2}\left(E_{11}, E_{21}, E_{22}, \varepsilon\right) \\
& \left(E_{22}-E_{22}^{(1)}\right) \bar{A}_{22}+\bar{A}_{22}^{T}\left(E_{22}-E_{22}^{(1)}\right) \\
& \quad=\varepsilon \mathscr{F}_{3}\left(E_{21}, E_{22}, \varepsilon\right)
\end{aligned}
$$

ここで, 関数 $\mathscr{F}_{1}, \mathscr{F}_{2}, \mathscr{F}_{3}$ は, $\varepsilon, E_{11}, E_{21}, E_{22}$ を適切に含む 陰関数である. $\bar{A}_{22}, \bar{A}_{0}$ は安定行列なので,

$$
\begin{aligned}
& \left\|E_{11}-E_{11}^{(1)}\right\|_{S}=O(\varepsilon), \quad\left\|E_{21}-E_{21}^{(1)}\right\|_{S}=O(\varepsilon) \\
& \left\|E_{22}-E_{22}^{(1)}\right\|_{S}=O(\varepsilon)
\end{aligned}
$$

となる。この操作を帰納的に $j=1,2,3, \cdots$ と続ければ,

$$
\begin{aligned}
\left\|H_{1}-H_{1}^{(j-1)}\right\|_{S} & =O\left(\varepsilon^{j}\right), . \quad\left\|H_{2}-H_{2}^{(j-1)}\right\|_{S}=O\left(\varepsilon^{j}\right) \\
\left\|H_{3}-H_{3}^{(j-1)}\right\|_{S} & =O\left(\varepsilon^{j}\right)
\end{aligned}
$$

に注意して,

$$
\begin{aligned}
& \left\|E_{11}-E_{11}^{(j)}\right\|_{s}=O\left(\varepsilon^{j}\right), \quad\left\|E_{21}-E_{21}^{(j)}\right\|_{s}=O\left(\varepsilon^{j}\right) . \\
& \left\|E_{22}-E_{22}^{(j)}\right\|_{s}=O\left(\varepsilon^{j}\right)
\end{aligned}
$$

となる。したがって，(18)が得られる，以上から，任意の初 期值に対して，とが小さいなら再帰的アルゴリズム $(17 \mathrm{a})$ $\sim(17 \mathrm{c})$ は収束する。.また，その収束解は $E_{11}, E_{21}, E_{22}$ であ る.

続いて, 再帰的アルゴリズムによってえられた解 $P_{\varepsilon}$ が準 正定かつ安定化解であることを示す. 通常, 文献 13)，14）な ぞで扱われている最適レギュレー夕問題や LQG 問題におい て, 最適ゲインを得るために解く必要がある摂動項を含むり カッチ方程式は，可制御性，可観測性が仮定されている. し たがって, 得られた解は準正定かつ安定化解を保証している. しかし，本論文で扱われているリカッチ方程式 (4) は, 可制 御性，可観測性を仮定しても，えられた収束解が準正定かつ 安定化解である保証がない.そこで, 再帰的アルゴリズム 17 a) 〜 (17 c) によってえられた解が準正定かつ安定化解である 証明を新たに行う。

この証明は， $\varepsilon=0$ の近傍における解 $P_{\varepsilon}$ が準正定かつ安定 化解であることを示すことと等価である.（19)から

$$
P_{\varepsilon}=\left[\begin{array}{cc}
\bar{P}_{11} & 0 \\
0 & 0
\end{array}\right]+O(\varepsilon)
$$

である. [仮定 3]，[仮定 4]から，リカッチ方程式(11 a)の解 $\bar{P}_{11}$ は準正定であるから $\varepsilon$ が十分小さいとき， $P_{\varepsilon}$ も準正定に なる. 続いて，

$$
\begin{aligned}
A_{\varepsilon} & -S_{\varepsilon}^{\gamma} P_{\varepsilon} \\
= & {\left[\begin{array}{cc}
A_{11} & A_{12} \\
\varepsilon^{-1} A_{21} & \varepsilon^{-1} A_{22}
\end{array}\right] } \\
& -\left[\begin{array}{cc}
S_{11}^{\gamma} P_{11}+S_{12}^{\gamma} P_{21} & \varepsilon S_{11}^{\gamma} P_{21}^{T}+S_{12}^{\gamma} P_{22} \\
\varepsilon^{-1}\left(S_{12}^{\gamma T} P_{11}+S_{22}^{\gamma} P_{21}\right) & \varepsilon^{-1}\left(\varepsilon S_{12}^{\gamma T} P_{21}^{T}+S_{22}^{\gamma} P_{22}\right)
\end{array}\right] \\
= & {\left[\begin{array}{cc}
\bar{A}_{11}+O(\varepsilon) & \bar{A}_{12}+O(\varepsilon) \\
\varepsilon^{-1}\left(\bar{A}_{21}+O(\varepsilon)\right) & \varepsilon^{-1}\left(\bar{A}_{22}+O(\varepsilon)\right)
\end{array}\right] }
\end{aligned}
$$

である. [仮定 3] から $\bar{A}_{22}$ は安定行列であり，関係式 (21) と [仮定 4]から $\overline{A_{0}}=\overline{A_{11}}-\overline{A_{12}} \overline{A_{22}} \overline{A_{21}}$ も安定行列である。した がって, 文献 11) から, 行列 (27) は安定となる. 以上から, 解 $P_{\varepsilon}$ が準正定かつ安定化解であることが示される.

次に, 再帰的アルゴリズムを $k$ 回繰り返してえられた解 $P_{\varepsilon}^{(k)}$ を用いて制御器を構成することを考える.このとき, 設 計された制御器に対して以下の定理をえることができる. 
《定理 $2 》 \gamma>\bar{\gamma}=\max \left\{\gamma_{s}, \gamma_{f}\right\}$ を満足するある $\gamma$ に対し て，リカッチ方程式(4)を再帰的アルゴリズム (17 a)〜 (17 c)にようて解いた解を $P_{\varepsilon}^{(k)}$ とする.このとき，（5）によって 構成された制御器 $u_{\text {pro }}=K_{\text {pro }} x$ は,

$$
\begin{aligned}
\|\left(C+D K_{\text {pro }}\right) \\
\quad \cdot\left(s I-A_{\varepsilon}-B_{2 \varepsilon} K_{\text {pro }}\right)^{-1} B_{1 \varepsilon} \|_{\infty} \\
=\|\left(C+D K_{\text {exa }}\right) \\
\quad \cdot\left(s I-A_{\varepsilon}-B_{2 \varepsilon} K_{\text {exa }}\right)^{-1} B_{1 \varepsilon} \|_{\infty}+O\left(\varepsilon^{k+1}\right) \\
<\gamma+O\left(\varepsilon^{k+1}\right)
\end{aligned}
$$

を満たす。ただし，

$$
\begin{aligned}
& K_{\text {exa }}=-B_{2 \varepsilon}^{T} P_{\varepsilon}, \quad K_{\text {pro }}=-B_{2 \varepsilon}^{T} P_{\varepsilon}^{(k)} \\
& P_{\varepsilon}^{(k)}=\left[\begin{array}{cc}
\bar{P}_{11}+\varepsilon E_{11}^{(k)} & \varepsilon\left(\bar{P}_{21}+\varepsilon E_{21}^{(k)}\right)^{T} \\
\varepsilon\left(\bar{P}_{21}+\varepsilon K_{21}^{(k)}\right) & \varepsilon\left(\bar{P}_{22}+\varepsilon E_{22}^{(k)}\right)
\end{array}\right]
\end{aligned}
$$

(定理 2 の証明) E. Fridman ${ }^{3}$ の Appendix に書かれてい る証明法を用いて不等式の評価を行う。まず，E. Fridman ${ }^{3)}$ と同様にして,リカッチ方程式 (4)の解 $P_{\varepsilon}$ を用いて，(5)に よって構築された制御器をシステム $(1 \mathrm{a}) \sim(1 \mathrm{~b})$ に適用す る.このとき, システム $(1 \mathrm{a}) \sim(1 \mathrm{~b})$ および, 評価関数 $(2)$ は, 以下の $(30 \mathrm{a}) \sim(30 \mathrm{~b})$ になる.

$$
\begin{aligned}
& \dot{x}=\hat{A}_{\varepsilon} x+\varepsilon F_{\varepsilon} x+B_{1 \varepsilon} w, \quad x(0)=0 \\
& J=\int_{0}^{\infty} x^{T}(t) \bar{Q} x(t) d t
\end{aligned}
$$

ここで,

$$
\begin{aligned}
\hat{A}_{\varepsilon} & =A_{\varepsilon}-B_{2 \varepsilon} B_{2}^{T} \bar{P} \\
& =A_{\varepsilon}-\left[\begin{array}{cc}
B_{1} B_{1}^{T} & B_{1} B_{2}^{T} \\
\varepsilon^{-1} B_{2} B_{1}^{T} & \varepsilon^{-1} B_{2} B_{2}^{T}
\end{array}\right]\left[\begin{array}{cc}
\bar{P}_{11} & 0 \\
\bar{P}_{21} & \bar{P}_{22}
\end{array}\right] \\
& =\left[\begin{array}{cc}
\hat{A}_{11} & \widehat{A}_{12} \\
\varepsilon^{-1} \widehat{A}_{21} & \varepsilon^{-1} \widehat{A}_{22}
\end{array}\right] \\
F_{\varepsilon} & =-\varepsilon^{-1} B_{2 \varepsilon}\left(B_{2 \varepsilon}^{T} P_{\varepsilon}-B_{2}^{T} \bar{P}\right)=\left[\begin{array}{c}
F_{1} \\
\varepsilon^{-1} F_{2}
\end{array}\right] \\
\bar{Q} & =Q+P_{\varepsilon} B_{2 \varepsilon} B_{2 \varepsilon}^{T} P_{\varepsilon}
\end{aligned}
$$

である. $\bar{A}_{22}=A_{22}-S_{22}^{\gamma} \bar{P}_{22}$ が安定より, $\hat{A}_{22}=A_{22}-B_{2} B_{2}^{T} \bar{P}_{22}$ は 安定行列であるから ${ }^{8)}$

$$
\begin{aligned}
& T^{-1} \widehat{A}_{\varepsilon} T=\left[\begin{array}{cc}
A_{s} & 0 \\
0 & \varepsilon^{-1} A_{f}
\end{array}\right], \quad y=T^{-1} x \\
& T=\left[\begin{array}{cc}
I_{n_{1}} & \varepsilon H \\
-L & I_{n_{2}}-\varepsilon L H
\end{array}\right] \\
& A_{s}=\widehat{A}_{11}-\widehat{A}_{12} L=\widehat{A}_{11}-\widehat{A}_{12} \hat{A}_{22}^{-1} \widehat{A}_{21}+O(\varepsilon) \\
& A_{f}=\widehat{A}_{22}+\varepsilon L \hat{A}_{12}=\widehat{A}_{22}+O(\varepsilon)
\end{aligned}
$$

である線形変換行列 $T$ が存在する ${ }^{10), 11)}$. ただし, $L, H$ は以 下の代数方程式 (32 a)〜 (32 b) の解である.

$$
\begin{aligned}
& \bar{A}_{22} L-\bar{A}_{21}-\varepsilon L\left(\bar{A}_{11}-\bar{A}_{12} L\right)=0 \\
& H\left(\bar{A}_{22}+\varepsilon L \bar{A}_{12}\right)-\bar{A}_{12}-\varepsilon\left(\bar{A}_{11}-\bar{A}_{12} L\right) H=0
\end{aligned}
$$

したがって, 線形変換 $(31)$ をシステム $(30 \mathrm{a})$ に適用するこ とによって, システム $(33 \mathrm{a}) \sim(33 \mathrm{~b})$ をえる.

$$
\begin{aligned}
& \dot{y}_{1}=A_{s} y_{1}+\varepsilon F_{s} y+B_{1 s} w, \quad y_{1}(0)=0 \\
& \varepsilon \dot{y}_{2}=A_{f} y_{2}+\varepsilon F_{f} y+B_{1 f} w, \quad y_{2}(0)=0
\end{aligned}
$$

$$
\begin{aligned}
& {\left[\begin{array}{c}
B_{1 s} \\
\varepsilon^{-1} B_{1 f}
\end{array}\right]=T^{-1} B_{1 \varepsilon}, \quad\left[\begin{array}{c}
F_{s} \\
\varepsilon^{-1} F_{f}
\end{array}\right]=T^{-1} F_{\varepsilon} T,} \\
& y=\left[\begin{array}{l}
y_{1}(t) \\
y_{2}(t)
\end{array}\right]
\end{aligned}
$$

である。

続いて, E. Fridman ${ }^{3)}$ が提案している制御器 $u_{m}=\left[V_{m}\right.$ $\left.+O\left(\varepsilon^{m}\right)\right] x$ の代わりに, 本論文で導出された再帰的解 $P_{\varepsilon}^{(k)}$ を 用いて，（5)によって構築した制御器 $u_{\text {pro }}$ をシステム (1 a) 〜 (1 b) に適用する.このときのシステム $(1 \mathrm{a}) \sim(1 \mathrm{~b})$ および, 評価関数 $(2)$ は，以下の $(34 \mathrm{a}) \sim(34 \mathrm{~b})$ になる.

$$
\begin{aligned}
& \dot{x}=\hat{A}_{\varepsilon} x+\varepsilon \hat{F}_{\varepsilon} x+B_{1 \varepsilon} w, \quad x(0)=0 \\
& \hat{J}=\int_{0}^{\infty} x^{T}(t) \hat{Q} x(t) d t
\end{aligned}
$$

ただし，

$$
\begin{aligned}
& \widehat{F}_{\varepsilon}=-\varepsilon^{-1} B_{2 \varepsilon}\left(B_{2 \varepsilon}^{T} P_{\varepsilon}^{(k)}-B_{2}^{T} \bar{P}\right)=\left[\begin{array}{c}
\hat{F}_{1} \\
\varepsilon^{-1} \widehat{F}_{2}
\end{array}\right], \\
& \widehat{Q}=Q+P_{\varepsilon}^{(k)} B_{2} B_{2}^{T} P_{\varepsilon}^{(k)}
\end{aligned}
$$

である. 同様に, $\bar{A}_{22}=A_{22}-S_{22}^{\gamma} \bar{P}_{22}$ は安定行列であるから, 線 形変換 $f=T^{-1} x$ をシステム $(34 \mathrm{a})$ に適用すれば, システム $(35 \mathrm{a}) \sim(35 \mathrm{~b})$ をえる.

$$
\begin{aligned}
& \dot{f}_{1}=A_{s} f_{1}+\varepsilon \widehat{F}_{s} f+B_{1 s} w, \quad f_{1}(0)=0 \\
& \varepsilon \dot{f}_{2}=A_{f} f_{2}+\varepsilon \hat{F}_{f} f+B_{1 f} w, \quad f_{2}(0)=0
\end{aligned}
$$

ただし，

$$
\begin{aligned}
& {\left[\begin{array}{c}
\widehat{F}_{s} \\
\varepsilon^{-1} \widehat{F}_{f}
\end{array}\right]=T^{-1} \widehat{F}_{\varepsilon} T,} \\
& f=\left[\begin{array}{l}
f_{1}(t) \\
f_{2}(t)
\end{array}\right]
\end{aligned}
$$

である。

本論文では, E. Fridman ${ }^{3)}$ と異なり, 直接的に 2 つの行列 (19) 及び(29)の差をとり, 定理 1 から以下の結果をえること ができる。

$$
\left\|P_{\varepsilon}-P_{\varepsilon}^{(k)}\right\|_{S}=O\left(\varepsilon^{k+1}\right)
$$

したがって,

$$
\begin{aligned}
& \left\|T^{-1} \widehat{F}_{\varepsilon} T-T^{-1} F_{\varepsilon} T\right\|_{S}=O\left(\varepsilon^{k}\right) \\
& \|\bar{Q}-\bar{Q}\|_{S}=O\left(\varepsilon^{k+1}\right)
\end{aligned}
$$

であることに注意すれば，シュワルツの不等式を利用するこ とによって,

$$
\begin{aligned}
|J-\hat{J}| \leq & \int_{0}^{\infty}\left[m_{1}|e(t)|_{E}|y(t)|_{E}+m_{2}|e(t)|_{E}|f(t)|_{E}\right. \\
& \left.+m_{0} \varepsilon^{k+1}|y(t)|_{E}|f(t)|_{E}\right] d t \\
\leq & \bar{m}\left[\|e\|_{2}\left(\|y\|_{2}+\|f\|_{2}\right)+\varepsilon^{k+1}\|y\|_{2} \cdot\|f\|_{2}\right]
\end{aligned}
$$

ただし，

$$
e(t)=y(t)-f(t)=\left[\begin{array}{l}
e_{1}(t) \\
e_{2}(t)
\end{array}\right]
$$

$\bar{m}=\max \left\{m_{0}, m_{1}, m_{2}\right\}$

$m_{1}=\left\|T^{T} \bar{Q} T\right\|_{s}>0, \quad m_{2}=\left\|T^{T} \hat{Q} T\right\|_{s}>0$

システム $(33 \mathrm{a}) \sim(33 \mathrm{~b})$ および, システム $(35 \mathrm{a}) \sim(35 \mathrm{~b})$ の差 を考えることによって, 以下のシステム $(40 \mathrm{a}) \sim(40 \mathrm{~b})$ を導 入する. 


$$
\begin{aligned}
& \dot{e}_{1}=A_{s} e_{1}+\varepsilon \hat{F}_{s} e+O\left(\varepsilon^{k+1}\right) y \\
& \varepsilon \dot{e}_{2}=A_{f} e_{2}+\varepsilon \hat{F}_{f} e+O\left(\varepsilon^{k+1}\right) y
\end{aligned}
$$

以上の準備のもとで，まず，微分方程式 $(33 \mathrm{~b})$ を解く.

$$
\begin{aligned}
\left\|y_{2}\right\|_{2}^{2} \leq & \int_{0}^{\infty} \int_{0}^{t} \int_{0}^{t} \frac{\beta_{2}}{\varepsilon^{2}} \exp \left[-\frac{\alpha_{2}}{\varepsilon}(2 t-r-p)\right] \\
& \cdot\left[|w(p)|_{E}+\varepsilon|y(p)|_{E}\right] \\
& \cdot\left[|w(r)|_{E}+\varepsilon|y(r)|_{E}\right] d r d p d t
\end{aligned}
$$

$\alpha_{2}, \beta_{2}$ はそれぞれ $\left\|\exp \varepsilon^{-1} A_{f} t\right\|_{s} \leq \beta_{2} \exp \left(-\varepsilon^{-1} \alpha_{2} t\right)$ を満たす 正の定数である，ここで，一般に成立する不等式

$$
\begin{aligned}
& {\left[|w(p)|_{E}+\varepsilon|y(p)|_{E}\right] \cdot\left[|w(r)|_{E}+\varepsilon|y(r)|_{E}\right]} \\
& \quad \leq \varepsilon^{2}\left[|y(p)|_{E}^{2}+|y(r)|_{E}^{2}\right]+|w(p)|_{E}^{2}+|w(r)|_{E}^{2}
\end{aligned}
$$

および，積分方程式 (41) の積分順序の変更をすることによっ て以下のように変形できる。

$$
\begin{aligned}
\left\|y_{2}\right\|_{2}^{2} \leq & \frac{2 \beta_{2}}{\varepsilon^{2}} \int_{0}^{\infty} \int_{p}^{\infty} \int_{0}^{t} \exp \left[-\frac{\alpha_{2}}{\varepsilon}(2 t-r-p)\right] \\
& d r d t \cdot\left[|w(p)|_{E}^{2}+\varepsilon^{2}|y(p)|_{E}^{2}\right] d p \\
\leq & \frac{2 \beta_{2}}{\alpha_{2}^{2}}\left[\|w\|_{2}^{2}+\varepsilon^{2}\|y\|_{2}^{2}\right]
\end{aligned}
$$

同様にして，微分方程式(33 a)を解けば.

$$
\left\|y_{1}\right\|_{2}^{2} \leq \frac{2 \beta_{1}}{\alpha_{1}^{2}}\left[\|w\|_{2}^{2}+\varepsilon^{2}\|y\|_{2}^{2}\right]
$$

をえることができる。したがって，\&が十分小さいときには，

$$
\|y\|_{2} \leq c_{1}\|w\|_{2}, \quad c_{1}>0
$$

が成立する.また， $(35 \mathrm{a}) \sim(35 \mathrm{~b}),(40 \mathrm{a}) \sim(40 \mathrm{~b})$ から,

$\|f\|_{2} \leq c_{2}\|w\|_{2}, \quad c_{2}>0$

$\|e\|_{2} \leq c_{3} \varepsilon^{k+1}\|y\|_{2}$

$$
\leq c_{4} \varepsilon^{k+1}\|w\|_{2}, \quad c_{3}, c_{4}>0
$$

がえられる.以上の結果から不等式 (46)〜 (47)を(39) に適用 すれば,

$$
\begin{aligned}
|J-\hat{J}| & \leq \bar{m}\left[\|e\|_{2}\left(\|y\|_{2}+\|f\|_{2}\right)+\varepsilon^{k+1}\|y\|_{2} \cdot\|f\|_{2}\right] \\
& \leq \bar{m}\left[c_{4}\left(c_{1}+c_{2}\right)+c_{1} \cdot c_{2}\right] \varepsilon^{k+1}\|w\|_{2}^{2} \\
& \leq \bar{m}_{0} \varepsilon^{k+1}\|w\|_{2}^{2}
\end{aligned}
$$

となるが, $J \leq \gamma^{2}\|w\|_{2}^{2}$ に注意すれば

$$
\begin{aligned}
& \hat{J}=J+O\left(\varepsilon^{k+1}\right)\|w\|_{2}^{2} \\
\Leftrightarrow & \hat{J} \leq\left[\gamma+O\left(\varepsilon^{k+1}\right)\right]^{2}\|w\|_{2}^{2}
\end{aligned}
$$

と等価である.

（注意 3）定理 2 の証明は，文献 3)の Theorem の証明と類 似している。しかし，本論文では，定理 1 からえられた関係 式(18)を利用して証明をおこなっているところが $\mathrm{E}$. Fridman $^{3)}$ と異なる，すなわち，文献 3) で提案されている制 御器 $u_{m}=\left[V_{m}+O\left(\varepsilon^{m}\right)\right] x$ が外部展開 (outer expantion)を利 用しているために， $\varepsilon$ の展開式になっている.つまり， $V_{m}=$ $-\sum \sum_{k=0}^{m} \varepsilon^{k}[\cdots]$ の形をしており, 文献 3)の Appendix の中に ある $Q_{m}-\bar{Q}=O\left(\varepsilon^{m+1}\right)$ などの関係式は外部展開からの結果 を利用して導出されている。一方，本論文では，(29)式の制 御器 $u_{\text {pro }}=K_{\text {pro }} x$ は再帰的アルゴリズムを利用している。そ の結果, 定理 1 からの結果である関係式 (36)，(37), 及び(38) などは全て (18) を利用して導出しているところが異なる.

さらに, 制御器の近似誤差を決定する要因が E. Fridman ${ }^{3)}$ と異なることが大きな特徴である。（ $u_{m}$ は設計者が展開した
次数 $m$ によって近似誤差が決まり, $u_{\text {pro }}$ は再帰的アルゴリズ 厶の反復回数 $k$ (収束回数 $k$ )によって近似誤差が決まるとこ ろが大きな違いになる.）また，微分係数の計算が必要ないの で, 制御器の設計が全て計算機によって可能である。

\section{4. 数 值 例}

簡単な数值例に対して上述のアルゴリズムを適用し，解を 求める.

システム $(1 \mathrm{a})$ ～(1 b) および, 評価関数 $(2)$ における各係 数行列を以下によって与える.ただし， $\varepsilon=0.0001$ である.

$$
\begin{aligned}
& A_{11}=\left[\begin{array}{cc}
0 & 0.4 \\
0 & 0
\end{array}\right], \quad A_{12}=\left[\begin{array}{cc}
0 & 0 \\
0.345 & 0
\end{array}\right] \\
& A_{21}=\left[\begin{array}{cc}
0 & -0.524 \\
0 & 0
\end{array}\right], \quad A_{22}=\left[\begin{array}{cc}
0 & 0.262 \\
0 & -1
\end{array}\right] \\
& B_{11}=\left[\begin{array}{l}
1 \\
0
\end{array}\right], \quad B_{12}=\left[\begin{array}{l}
0.2 \\
1.2
\end{array}\right] \\
& B_{21}=\left[\begin{array}{l}
0 \\
0
\end{array}\right], \quad B_{22}=\left[\begin{array}{l}
0 \\
1
\end{array}\right] \\
& Q=C^{T} C=\operatorname{diag}\{1,0,1,0\} \\
& C^{T}=\left[\begin{array}{llllll}
1 & 0 & 0 & 0 & 0 & 0 \\
0 & 0 & 0 & 0 & 0 & 0 \\
0 & 0 & 1 & 0 & 0 & 0 \\
0 & 0 & 0 & 0 & 0 & 0
\end{array}\right] \\
& D^{T}=\left[\begin{array}{lllll}
0 & 0 & 0 & 0 & 1
\end{array}\right]
\end{aligned}
$$

このとき, 2 次評価関数は以下になる.

$$
J=\int_{0}^{\infty}\left[x^{T}(t) Q x(t)+u^{T}(t) u(t)\right] d t
$$

システム $(1 \mathrm{~b})$ における行列 $A_{22}$ の行列式 $\operatorname{det} A_{22}$ は, $\operatorname{det} A_{22}$ $=0$ なので非標準特異摂動システムである.

まず, $\gamma_{f}=0.7680, \gamma_{s}=7.0817$ であるので， $\varepsilon$ が分小さい とき $\gamma>\bar{\gamma}=\max \left\{\gamma_{s}, \gamma_{f}\right\}=7.0817$ を満足するある $\gamma$ に対し て，一般化リカッチ方程式 (7 a ) (7 b) は準正定である安定 化解をもつことがわかる. したがって，本論文では， $\gamma=8>$ テとして設計する.

はじめに,一般化リカッチ方程式 (7 a ) (7b)に対して $\varepsilon=$ .0 とおくことによってえられる 0 -オーダ解 $P^{(0)}$ ，および制御 ゲイン $K_{0}$ は以下によって与えられる。

$$
\begin{aligned}
P^{(0)} & =\left[\begin{array}{rlcc}
14.85007 & 6.26150 & 0 & 0 \\
6.26150 & 8.74375 & 0 & 0 \\
12.54696 & 5.27678 & 4.86116 & 1.03771 \\
2.77242 & 0.72567 & 1.03771 & 0.24405
\end{array}\right] \\
K_{0} & =\left[\begin{array}{llll}
-2.77242 & -0.72567 & -1.03771 & -0.24405
\end{array}\right]
\end{aligned}
$$

ここで，注意しなければならないことは，制御ゲイン $K_{0}$ は， E. Fridman ${ }^{3)}$ の提案している制御ゲイン $V_{0}$ に一致すること である．続いて，本論文で提案されたアルゴリズムを上述の 問題に適用すれば，4回の繰り返し計算によって次の一般化 リカッチ方程式 $(7 \mathrm{a}) \sim(7 \mathrm{~b})$ の再帰的解 $P^{(k)}\left(P_{\varepsilon}^{(k)}=\bar{D}^{T} P^{(k)}\right)$, および制御ゲイン $K_{\text {pro }}$ をえることができる. 


$$
\begin{aligned}
P^{(k)} & =\left[\begin{array}{rrrr}
14.85237 & 6.26272 & 0.00126 & 0.00028 \\
6.26272 & 8.74439 & 0.00053 & 0.00007 \\
12.54901 & 5.27789 & 4.86227 & 1.03794 \\
2.77286 & 0.72592 & 1.03794 & 0.24411
\end{array}\right] \\
K_{\text {pro }} & =\left[\begin{array}{llll}
-2.77286 & -0.72592 & -1.03794 & -0.24411
\end{array}\right]
\end{aligned}
$$

本論文では，収束の判定は $\left\|P^{(j+1)}-P^{(j)}\right\|_{S}<10^{-7}, j=1,2, \cdots$ となったところで計算を打ち切る. 一般化リカッチ方程式の 解の精度を比較するために, MATLAB を用いて直接りカッ チ方程式 ( 4 )を分割計算することなく解いた解 $P_{\varepsilon}$, および制 御ゲイン $K_{\text {exa }}$ を以下によって与える.

$$
P_{\varepsilon}=\left[\begin{array}{rrrr}
14.8509 & 6.2620 & 0.0013 & 0.0003 \\
6.2620 & 8.7440 & 0.0005 & 0.0001 \\
0.0013 & 0.0005 & 0.0005 & 0.0001 \\
0.0003 & 0.0001 & 0.0001 & 0.0000
\end{array}\right]
$$

$$
K_{\text {exa }}=\left[\begin{array}{llll}
-2.7726 & -0.7258 & -1.0379 & -0.2441
\end{array}\right]
$$

最後に， $\gamma=8$ で設計した制御器に対する式( 3 )による $H_{\infty}$ ) ルムの值は以下のとおりである。

$$
\begin{aligned}
& \gamma_{0}=7.8729 \\
& \gamma_{\text {pro }}=7.8727 \\
& \gamma_{\text {exa }}=7.8729 \\
& \gamma_{\text {opt }}=7.0484
\end{aligned}
$$

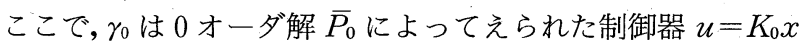
をシステム $(1 \mathrm{a}) \sim(1 \mathrm{~b})$ に入力したときの式 ( 3 )で与えられ る $H_{\infty}$ ノルムの值である. あるいは, E. Fridman ${ }^{3)}$ の提案し ている制御ゲイン $V_{0}$ を入力したときの $H_{\infty}$ ノルムの值と解 釈できる.同様に $\gamma_{\text {pro }}$ は提案型の方法を利用してえられた解 $P_{\varepsilon}^{(k)}$ による $H_{\infty}$ ノルムの值. $\gamma_{\text {exa }}$ は直接リカッチ方程式 (4) を $\gamma=8$ として得られた解 $P_{\varepsilon}$ による $H_{\infty}$ ノルムの值を意味 する. 最後の $\gamma_{o p t}$ は， $\varepsilon=0.0001$ としたときのシステム $(1 \mathrm{a})$ 〜 (1 b) に関するリカッチ方程式 ( 4 ) が準正定である安定化 解をもつための $\gamma$ の下限值である.

これらの結果を比較する。まず, 0 -オーダ解 $\bar{P}_{0}$ によってえ られた制御器 $u=K_{0} x$ をシステムに入力したときの $H_{\infty}$ ノル ムの值 $\left(\mathrm{E}\right.$. Fridman $\left.^{3}\right)$ の提案している制御ゲイン $V_{0}$ を入力 したときの $H_{\infty}$ ノルムの值) $\gamma_{0}$, 提案型の方法を利用してえら れた制御器による $H_{\infty}$ ノルムの值 $\gamma_{\text {pro }}$, MATLAB を用いて, 直接リカッチ方程式 $(4)$ を $\gamma=8$ としてえられた制御器を入 力したときの $H_{\infty}$ ノルムの值 $\gamma_{\text {exa }}$ のいずれも, $\varepsilon=0.0001$ と したときの $\gamma_{o p t}$ より大きいが, 設計前の $\gamma=8$ より小さく なっていることが確認される.

さらに, 本論文で提案されたアルゴリズムで得られた解 $P_{\varepsilon}^{(k)}$ は, リカッチ方程式を直接解いてえられた解 $P_{\varepsilon}$ に限り なく近づく.つまり，

$$
P_{\varepsilon}^{(k)} \rightarrow P_{\varepsilon}
$$

したがって一般化リカッチ方程式の解が $10^{-3}$ オーダの範囲 でえられた結果は妥当であることがわかる．また，制御入力 および，そのときの $H_{\infty}$ ノルムの值に関しても $10^{-3}$ オーダの 範囲で一致していることがわかる. 以上から, 数值例からも 定理 2 における $H_{\infty}$ ノルムの不等式(28)を確認することがで
きる。

(注意 4) E. Fridman ${ }^{3}$ の提案している high-order である 制御器 $u_{m}$ (文献 3$)$ の (3.8) 式) は, $m=0$ の場合 $\left(u=u_{0}\right)$, 本論 文の 0 -オーダ解を利用した制御器 $u=K_{0} x$ と一致する. しか し, $1 \leq m$ の場合, E. Fridman ${ }^{3)}$ の提案している high-order である制御器を構築することは, 本論文の数值例では, 微分 係数の計算など困難なため, 制御器をえることは実際に難し い. したがって, 本論文では, $u=K_{0} x=u_{0}$ を入力したときの $H_{\infty}$ ノルムの比較を行っている. その結果, 本論文の数值例で

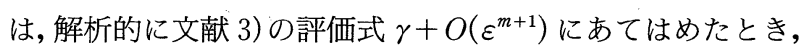
E. Fridman の制御器 $u_{m}=u_{0}$ では $\gamma+O(\varepsilon)$ しか達成されな い. しかし, 本論文で提案された制御器の場合, 評価式 $\gamma$ $+O\left(\varepsilon^{k+1}\right)$ は反復回数 $k$ に依存しており, 本論文の数值例の 場合 $k=4$ で収束しているので, $\gamma+O\left(\varepsilon^{5}\right)$ を達成しているこ とがわかる。

\section{5. ま と め}

本論文では, $A_{22}^{-1}$ の存在を仮定しない標準, 非標準特異摂動 システムにおける $H_{\infty}$ 制御問題に対して，一般化リカッチ方 程式を利用した再帰的アルゴリズムの手法による制御器の構 築を提案した。再䚻的アルゴリズムを利用することにより， 摂動項 $\varepsilon$ が十分小さいとき，えられた一般化りカッチ方程式 の解は準正定かつ安定化解であることを証明した。さらに， 直接 full-order system における一般化リカッチ方程式の解 を $O\left(\varepsilon^{k}\right)$ の高精度で解くことによって, 構築された制御器は $O\left(\varepsilon^{k}\right)$ の高精度であることを同時に示した。その結果, 特異摂 動法による近似解を利用した制御器に比べて，より最適な制 御が可能となった。つまり再帰的アルゴリズムによってえら れた制御器は, 設計仕様の $\gamma$ に対して $\gamma+O\left(\varepsilon^{k+1}\right)$ を保証し ている.さらに，本論文では，アルゴリズムの有効性を検証 するため, 数值例に適用し解を求めた。このとき, 再帰的ア ルゴリズムによってえられた一般化リカッチ方程式の解で構 成される制御器が，数值的に十分有効であることが確認され た。

\section{参: 考 文 献}

1) Z. Pan and T. Basar: $H_{\infty}$-Optimal Control for Singularly Perturbed Systems-Part I. Pperfect state mesurements, Automatica, 29-2, 401/423(1993)

2) Z. Pan and T. Basar: $H_{\infty}$-Optimal Control for Singularly Perturbed Systems-Part II. Imperfect state mesurements, IEEE Trans. Automatic Control, 39-2, 230/299(1994)

3) E. Fridman: Near-Optimal $H_{\infty}$-Control of Linear Singularly Perturbed Systems, IEEE Trans. Automatic Control, 41-2, 236/240 (1996)

4) V. Dragan: $H_{\infty}$-Norms and Disturbance Attenuation for Systems with Fast Transients, IEEE Trans. Automatic Control, 41-5, 747/750 (1996)

5) J. C. Doyle, K. Glover, P. P. Khargonekar, and B. A. Francis: State Space Solution to Standard $H_{2}$, and $H_{\infty}$ Control Ploblems, IEEE Trans. Automatic Control, 34-8, 831/847 (1989)

6) G. Hewer: Existence Theorems for Positive Semidefinite 
and Sign Indefinite Stabilizing Solutions of $H_{\infty}$ Riccati Equations, SIAM J. Control and Optimization, 31, 16/ 29(1993)

7) Z. Gajic and M. T. J. Qureshi : Lyapunov Matrix Equation in Syatem Stabilty and Control, Academic Press. Vol. 195 (1995)

8) P. Lancaster and L. Rodman: Algebraic Riccati Equations, Clarendon Press • Oxford (1995)

9) Z. Gajic, D. Petkovski and X. Shen: Singularly Perturbed and Weakly Coupled Linear System-a Recursive Approach, Lecture Notes in Control and Infomation Sciences, 140, Berlin ; Springer-Verlag (1990)

10) W. C. Su, Z. Gajic, and X. Shen: The exact slow-fast decomposition of the algebraic Riccati equation of singularly perturbed systems, IEEE Trans. Automatic Control, 37-9, 1456/1459(1992)

11) P. V. Kokotovic, H. K. Khalil and J. O'Reilly: Singular Perturbation Methods in Control: Analysis and Design; Academic Press (1986)

12) $\mathrm{H}$. $\mathrm{Xu}$ and $\mathrm{K}$. Mizukami : Nonstandard extension of $H_{\infty}$-optimal control for singularly perturbed systems; Proceeding of the 7th International Symposium on Dynamic Games and Applications, December 16-18, Japan(1996)

13）向谷, 水上, 徐：非標準特異摂動システムにおける最適レギュ レータ問題のための再㷌的アルゴリズム，計測自動制御学会 論文集, 32-5，672/678(1996)

14）向谷, 水上：非標準特異摂動システムに抢けるLinearQuadratic-Gaussian(LQG) 問題のための再帰的アルゴリズ 厶，電気学会論文誌 C，116-C-12，1382/1389(1996)
[著 者 紹 介]

向 谷 博 明(正会員)

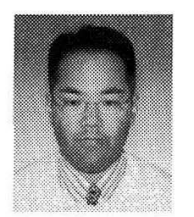

1992 年広島大学総合科学部数理情報学専攻卒 業. 97 年 10 月同大学大学院工学研究科情報工学 専攻博士課程修了. 博士 (工学). 98 年 4 月広島市 立大学情報科学部助手, 現在に至る。ロバスト制 御, アルゴリズムに関する研究に従事. 電気学会 会員.

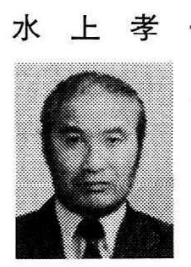

一(正会員)

1958 年, 広島大学工学部電気工学科卒業. 60 年 京都大学大学院工学研究科電気工学専攻修士課程 修了. 63 年京都大学工学部助手, トロント大学客 員研究員などを経て, 68 年広島大学工学部助教 授, 77 年同総合科学部教授, 同大学院工学部研究 科担当, 現在に至る. 関数解析, 最適制御, 微分 ゲーム, 情報検索などの研究に従事（工学博士）。 情報処理学会, システム制御情報学会などの会員.

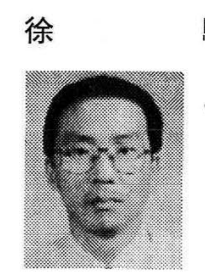

\section{驊 (正会員)}

1982 年中国東北大学自動制御学部工業自動化 専攻卒業. 85 年同大学大学院自動制御専攻修士課 程修了. 93 年広島大学大学院工学研究科情報工学 専攻博士課程 (後期) 修了. 同年広島大学総合科学 部助手. 96 年 4 月同学部助教授となり現在に至 る. 最適制御，動的ゲームとその応用に関する研 究に従事(工学博士). 